\title{
White Matter Microstructure in Transsexuals and Controls Investigated by Diffusion Tensor Imaging
}

\author{
Georg S. Kranz, ${ }_{1}^{1}$ Andreas Hahn, ${ }^{1}$ Ulrike Kaufmann, ${ }^{2}$ Martin Küblböck, ${ }^{3}$ Allan Hummer, ${ }^{3}$ Sebastian Ganger, ${ }^{1}$ \\ Dene Seiger, ${ }^{1}$ Dietmar Winkler, ${ }^{1}$ Dick F. Swaab ${ }^{4}$ Christian Windischberger, ${ }^{3}$ Siegfried Kasper, ${ }^{1}$ \\ and Rupert Lanzenberger ${ }^{1}$ \\ Departments of ${ }^{1}$ Psychiatry and Psychotherapy and ${ }^{2}$ Obstetrics and Gynecology, and ${ }^{3} \mathrm{MR}$ Centre of Excellence, Center for Medical Physics and Biomedical \\ Engineering, Medical University of Vienna, 1090 Vienna, Austria, and ${ }^{4}$ Netherlands Institute for Neuroscience, An Institute of the Royal Netherlands \\ Academy of Arts and Sciences, 1105 BA Amsterdam, The Netherlands
}

\begin{abstract}
Biological causes underpinning the well known gender dimorphisms in human behavior, cognition, and emotion have received increased attention in recent years. The advent of diffusion-weighted magnetic resonance imaging has permitted the investigation of the white matter microstructure in unprecedented detail. Here, we aimed to study the potential influences of biological sex, gender identity, sex hormones, and sexual orientation on white matter microstructure by investigating transsexuals and healthy controls using diffusion tensor imaging (DTI). Twenty-three female-to-male (FtM) and 21 male-to-female (MtF) transsexuals, as well as 23 female (FC) and 22 male (MC) controls underwent DTI at 3 tesla. Fractional anisotropy, axial, radial, and mean diffusivity were calculated using tract-based spatial statistics (TBSS) and fiber tractography. Results showed widespread significant differences in mean diffusivity between groups in almost all white matter tracts. FCs had highest mean diffusivities, followed by FtM transsexuals with lower values, MtF transsexuals with further reduced values, and MCs with lowest values. Investigating axial and radial diffusivities showed that a transition in axial diffusivity accounted for mean diffusivity results. No significant differences in fractional anisotropy maps were found between groups. Plasma testosterone levels were strongly correlated with mean, axial, and radial diffusivities. However, controlling for individual estradiol, testosterone, or progesterone plasma levels or for subjects' sexual orientation did not change group differences. Our data harmonize with the hypothesis that fiber tract development is influenced by the hormonal environment during late prenatal and early postnatal brain development.
\end{abstract}

Key words: diffusion tensor imaging; gender identity disorder; testosterone; transsexual; white matter microstructure

\section{Introduction}

Numerous neuroimaging studies have revealed that females and males differ with respect to brain function and structure. Several of these studies use diffusion tensor imaging (DTI), a magnetic resonance imaging method that yields quantitative measures, including the degree of anisotropy [fractional anisotropy (FA)] and axial (AD), radial (RD), and mean (MD) diffusivities (JohansenBerg and Behrens, 2009). Studies investigating sex effects on white matter microstructure using DTI have revealed several regions in which diffusivity measures differed between women and men. In a sample of 857 healthy subjects, Inano et al. (2011)

\footnotetext{
Received June 18, 2014; revised Sept. 16, 2014; accepted 0ct. 2, 2014.

Author contributions: G.S.K., U.K., D.W., D.F.S., C.W., S.K., and R.L. designed research; G.S.K., U.K., M.K., A.Hu., and D.W. performed research; G.S.K., A.Ha., M.K., S.G. and R.S. analyzed data; G.S.K., A.Ha., D.F.S., C.W., S.K., and R.L. wrote the paper.

This study was supported by Austrian Science Fund Grant 23021 (R.L.). We thank E. Akimova, C. Kraus, P. Baldinger, A. Höflich, T. Vanicek, A. Kautzky, A. Komorowski, U. Moser, E. K. Tempfer-Bentz, and C. Tempfer for their medical support and M. Spies for native English editing. We are especially grateful to all transsexual subjects for participating in this study.

The authors declare no competing financial interests.

Correspondence should be addressed to Dr. Rupert Lanzenberger, Functional, Molecular, and Translational Neuroimaging Lab, Department of Psychiatry and Psychotherapy, Medical University of Vienna, Waehringer Guertel 18-20, 1090 Vienna, Austria. E-mail: rupert.lanzenberger@meduniwien.ac.at.

DOI:10.1523/JNEUROSCI.2488-14.2014

Copyright $\odot 2014$ the authors $\quad 0270-6474 / 14 / 3415466-10 \$ 15.00 / 0$
}

found higher $\mathrm{FA}$ and $\mathrm{AD}$ in males in multiple regions, whereas higher RD was more widespread in females. Although brain structural sex dimorphisms have been linked to hormonal differences between the sexes during fetal development (Chou et al., 2011), puberty (Herting et al., 2012), or adulthood (Witte et al., 2010), the specific biological mechanisms underlying these differences remain to be determined.

According to the organization/activation theory, hormonal influences during late prenatal and early postnatal brain development determine the sexual imprint of the brain. The presence or absence of testosterone ( $\mathrm{T}$ ) during the second half of pregnancy is believed to shape our brains toward male or female, respectively (Swaab and Garcia-Falgueras, 2009; Bao and Swaab, 2011). Although direct genetic influences can also affect sexual brain differentiation without the involvement of sex hormones, it is assumed that brain organization underlying a subject's gender identity is dependent on hormonal influences during fetal development (Swaab and Garcia-Falgueras, 2009). Furthermore, because sexual brain differentiation is temporally differentiated from sexual differentiation of the genitals, both processes can be influenced independently, which may result in transsexuality (Swaab and Garcia-Falgueras, 2009). Hence, it is assumed that the transgender identity in these subjects results from a mismatch between gender-specific brain development and the develop- 
Table 1. Hormone levels, sexual orientation, and volumetric data

\begin{tabular}{|c|c|c|c|c|}
\hline & $\mathrm{FCs}$ & FtM transsexuals & MtF transsexuals & MCs \\
\hline$n$ & 23 & 23 & 21 & 22 \\
\hline $\mathrm{E}_{2}(\mathrm{pg} / \mathrm{ml})$ & $110.86 \pm 130.82^{c, d}$ & $100.00 \pm 70.10^{c, d}$ & $28.70 \pm 17.69^{a, b}$ & $26.62 \pm 9.66^{a, b}$ \\
\hline $\mathrm{T}(\mathrm{ng} / \mathrm{ml})$ & $0.29 \pm 0.14^{c, d}$ & $0.38 \pm 0.18^{c, d}$ & $4.94 \pm 2.22^{a, b}$ & $5.31 \pm 1.89^{a, b}$ \\
\hline $\mathrm{P}_{4}(\mathrm{ng} / \mathrm{ml})$ & $0.81(0.41 / 7.44)$ & $1.18(0.72 / 9.76)^{c, d}$ & $0.59(0.48 / 0.80)^{c}$ & $0.74(0.61 / 0.90)^{c}$ \\
\hline \multicolumn{5}{|c|}{ Sexual orientation (n) } \\
\hline Females & 5 & 19 & 4 & 16 \\
\hline Males & 15 & 1 & 5 & 6 \\
\hline Bisexual & 3 & 3 & 12 & 0 \\
\hline GMV (ml) & $630.32 \pm 52.37^{c, d}$ & $633.86 \pm 50.58^{d}$ & $671.81 \pm 48.55^{a}$ & $712.89 \pm 48.64^{a, b}$ \\
\hline WMV (ml) & $489.57 \pm 42.22^{c, d}$ & $497.91 \pm 54.83^{c, d}$ & $538.65 \pm 57.19^{a, b}$ & $578.45 \pm 42.99^{a, b}$ \\
\hline CSF (ml) & $214.45 \pm 16.81^{c, d}$ & $212.47 \pm 22.05^{c, d}$ & $242.56 \pm 36.29^{a, b}$ & $245.16 \pm 34.29^{a, b}$ \\
\hline TIV (ml) & $1334.35 \pm 83.45^{c, d}$ & $1344.24 \pm 104.17^{c, d}$ & $1453.02 \pm 117.71^{a, b}$ & $1536.49 \pm 113.57^{a, b}$ \\
\hline
\end{tabular}

$E_{2}$ and T plasma levels per group are given in means \pm SDs. $P_{4}$ plasma levels are given as medians and quartiles because of non-normal distribution in all groups except for MC (assessed using Kolmogorov-Smirnov test, $p<0.05$ ). Genetic females had significantly higher $\mathrm{E}_{2}$ and significantly lower T plasma levels compared with genetic males (assessed using ANOVA and post hoc $t$ test, $p<0.05$, Bonferroni's corrected). No differences were observed between $\mathrm{F}(s$ and FtM transsexuals and between MtF transsexuals and MCs ( $p>0.1$, uncorrected). $P_{4}$ plasma levels were significantly higher in FtM transsexuals compared with MtF transsexuals and MCs but similar for other group comparisons (assessed using Kruskal-Wallis test and posthoc pairwise comparisons using Mann-Whitney U test, $p<0.01$, Bonferroni's corrected). Sexual orientation is given in numbers of participants attracted toward females or males or having a bisexual orientation. Sexual orientation ratings were assessed using a Likert scale from 1 (females) to 7 (males), where values 1 and 2 are combined as attraction towards females, 3-5 denote a bisexual orientation, and 6 and 7 denote attraction towards males. Volumetric data include GMV, WMV, CSF, and the sum of the three volumes, denoted as TIV. As expected, volumes were significantly larger in genetic males than genetic females (assessed using ANOVA and post hoc $t$ test, $p<0.05$, Bonferroni's corrected). Interestingly, except for CSF, volumes exhibited the transition $\mathrm{FC}<\mathrm{FtM}<\mathrm{MtF}<\mathrm{MC}$.

${ }^{a}$ Significant difference to $\mathrm{FC}, p<0.05$, Bonferroni's corrected.

${ }^{b}$ Significant difference to FtM transsexuals, $p<0.05$, Bonferroni's corrected.

'Significant difference to MtF transsexuals, $p<0.05$, Bonferroni's corrected.

${ }^{d}$ Significant difference to MCs, $p<0.05$, Bonferroni's corrected.

ment of body and genitals. Investigating transsexual subjects before they receive hormonal treatment thus provides the unique opportunity to differentiate brain structural features that underlie a person's gender identity from those that are defined by a person's biological sex.

As of yet, only two studies have investigated white matter microstructure in transsexuals (Rametti et al., 2011a,b). These investigations report increased FA values in male controls (MCs) compared with female controls (FCs) in several regions in the right hemisphere. Interestingly, female-to-male (FtM) and male-tofemale $(\mathrm{MtF})$ transsexuals exhibited FA values between those of MCs and FCs. Furthermore, these values were often more similar to those of their desired rather than their genetic sex. The authors interpreted their findings as increased masculinization in FtM transsexuals and incomplete masculinization in MtF transsexuals. Although these data are very promising, knowledge on additional determinants of observed differences is missing.

Hence, the aim of the present study was to investigate the white matter microstructure in FtM and MtF transsexuals and FCs and MCs by comparing FA, MD, AD, and RD maps. These measures were then related to gender identity and genetic sex, as well as individual sex hormone levels and sexual orientation.

\section{Materials and Methods}

Participants. Eighty-nine participants were included in this crosssectional study consisting of $23 \mathrm{FCs}, 23 \mathrm{FtM}$ transsexuals, $21 \mathrm{MtF}$ transsexuals, and 22 MCs. Data from a subsample of subjects have been published in two previous studies (Hahn et al., 2014; Kranz et al., 2014). Subjects' age ranged between 18 and 45 years, with mean \pm SD values as follows: FCs, $25.96 \pm 6.07$ years; FtM transsexuals, $25.91 \pm 6.83$ years; $\mathrm{MtF}$ transsexuals, $30.86 \pm 8.38$ years; and MCs, $25.45 \pm 4.76$ years. MtF transsexuals were on average 5 years older than FtM transsexuals and control subjects ( $p=0.03$, ANOVA), which is in accordance with epidemiological data from other western European countries (De Cuypere et al., 1995; van Kesteren et al., 1996) showing that FtM transsexuals present to a first consultation at an earlier age than MtF transsexuals. To rule out physical, psychiatric, and neurological disorders (except for gender identity disorder in transsexuals), all subjects underwent standard medical examination, electrocardiogram, routine laboratory tests, and the Structured Clinical Interview for Diagnostic and Statistical Manual of
Mental Disorders, Fourth Edition (DSM-IV) disorders (American Psychiatric Association, 2000). Additional exclusion criteria were past or current substance abuse, intake of psychotropic medication, pregnancy, and hormonal treatment, including oral contraceptives (tested with multidrug screen test panel and human chorionic gonadotropin pregnancy test at the screening visit and before the MR scan). Diagnostic assessment of gender identity disorder followed DSM-IV (text revision) and International Classification of Diseases, 10th Revision and was made after several semistructured, sociodemographic, clinical, and psychiatric interviews, based on legal requirements for cross-sex hormonal treatment in Austria. All transsexuals were recruited from the transgender outpatient unit of the Department of Obstetrics and Gynecology, Medical University of Vienna, were naive to steroid hormone treatment, and wanted sex reassignment. All of them reported experiencing gender dysphoria at a relatively early age (before or at puberty). Control subjects were recruited by advertisement at the Medical University of Vienna. All participants received financial compensation for their participation. After complete description of the study to the subjects, written informed consent was obtained. The study was approved by the Ethics Committee of the Medical University of Vienna.

Serum sampling and determination of subjects' sexual orientation. Blood samples were collected before MR scans. The analysis of plasma levels of estradiol $\left(\mathrm{E}_{2}\right), \mathrm{T}$, and progesterone $\left(\mathrm{P}_{4}\right)$ was done by the Department of Laboratory Medicine, Medical University of Vienna (http://www.kimcl. at). Sexual orientation was determined using a modified version of the Klein Sexual Orientation Grid (Klein et al., 1985) at the screening visit. Here, we used sexual attraction ratings toward the female or male gender, assessed on a seven-point Likert scale as a measure for sexual orientation (Table 1).

MR protocol. Participants underwent a $4.56 \mathrm{~min}$ whole-brain diffusion-weighted image (DWI) scan on a 3 T TIM Trio Scanner (Siemens) using a 32-channel head coil. Polyurethane cushions placed between the head coil and subjects' head minimized head movement. DWI was acquired with a single-shot diffusion-weighted echo planar imaging sequence (TE, $83 \mathrm{~ms}$; TR, $8700 \mathrm{~ms}$; flip angle, $90^{\circ}$; image resolution, 1.64 $\mathrm{mm}$ isotropic; $b$ value, $800 \mathrm{~s} / \mathrm{mm}^{2} ; 70$ axial slices) in 30 diffusionencoding directions and one nondiffusion weighted $b 0$ image. In addition, structural images were acquired in the same scanning session. Here, a T1-weighted magnetization prepared rapid gradient echo sequence was used (TE, $4.2 \mathrm{~ms}$; TR, $2300 \mathrm{~ms}$; spatial resolution, $1.1 \times 1 \times 1 \mathrm{~mm}$; scan time, $7.45 \mathrm{~min}$ ). A clinical neuroscientist with extensive neuroradiological experience (R.L.) checked the T1-weighted images for lesions and 


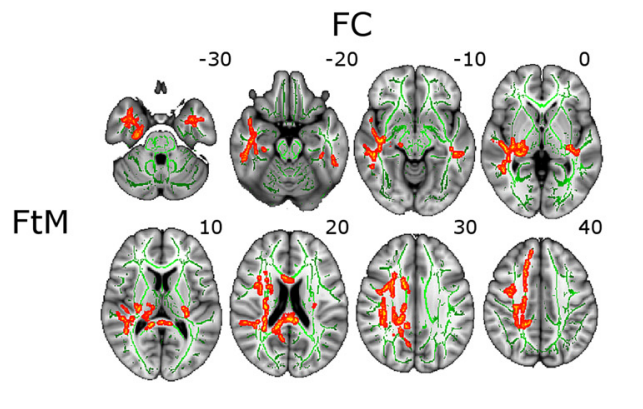

\section{MEAN DIFFSUIVITY}
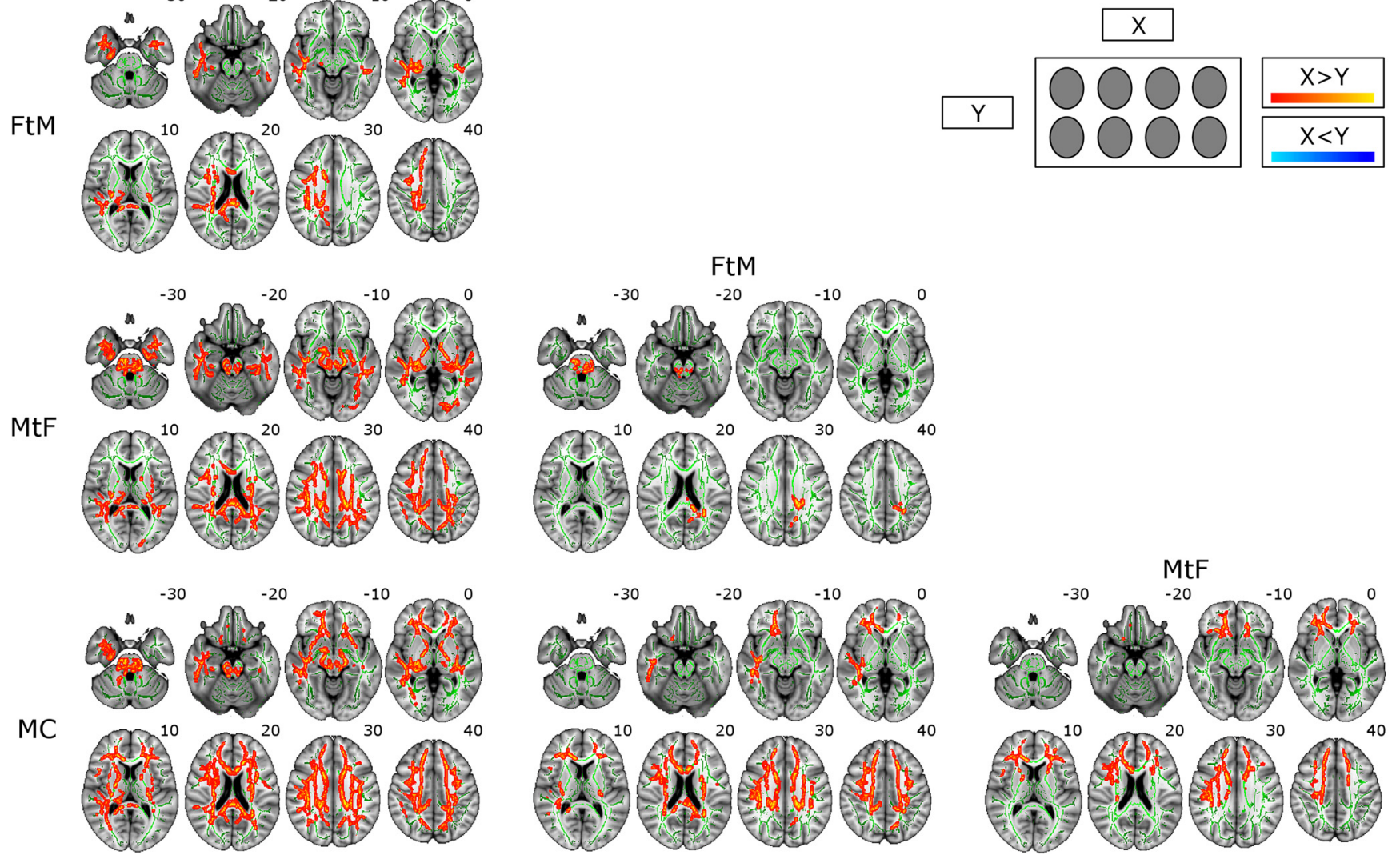

Figure 1. Effects of gender identity and sex on regional MD. Depicted are pairwise comparisons between the four study groups (FCs, MCs, FtM transsexuals, and MtF transsexuals), overlaid onto eight axial planes (from $z=-30$ to $40 \mathrm{~mm}, \mathrm{MNI}$ space); see schema on the top right. Six comparisons, from top to bottom: $\mathrm{FC}>\mathrm{FtM}, \mathrm{FC}>\mathrm{MtF}$, FC $>\mathrm{MC}$ (first column); FtM $>M \mathrm{MtF}$, FtM $>\mathrm{MC}$ (second column); and MtF $>$ MC (third column), e. g. white matter tracts in red-yellow show significantly higher MD in FCs compared with FtM transsexuals in the top left comparison ( $p<0.05$, FWE corrected). Left is right.

structural malformations to ensure that brain scans were void of morphological abnormalities.

Image analysis. FA and $\mathrm{MD}$ are derived from the principal diffusivities $\lambda_{1}, \lambda_{2}$, and $\lambda_{3}$, whereby $\mathrm{AD}$ equals the eigenvalue of the primary eigenvector $\left(\lambda_{1}\right)$ and $\mathrm{RD}$ equals the average of the two smaller eigenvalues, with the diffusion coefficients assumed to be perpendicular to the fiber $\left(\lambda_{2}+\lambda_{3} / 2\right)$. FA is calculated using the following formula:

$$
\mathrm{FA}=\sqrt{\frac{\left(\lambda_{1}-\mathrm{MD}\right)^{2}+\left(\lambda_{2}-\mathrm{MD}\right)^{2}+\left(\lambda_{3}-\mathrm{MD}\right)^{2}}{2\left(\lambda_{1}^{2}+\lambda_{2}^{2}+\lambda_{3}^{2}\right)}}
$$

with

$$
\mathrm{MD}=\frac{\lambda_{1}+\lambda_{2}+\lambda_{3}}{3}
$$

Calculation of the $\mathrm{FA}, \mathrm{MD}, \mathrm{AD}$, and $\mathrm{RD}$ maps was performed with the FMRIB (Functional MRI of the Brain) software library (FMRIB Software Library version 5.0.5; http://fsl.fmrib.ox.ac.uk/fsl/fslwiki/) using tractbased spatial statistics (TBSS) (Smith et al., 2006) with default parameters unless specified otherwise. This included adjustment for eddy currents and head movement, as well as removal of the skull and nonbrain tissue with the brain extraction tool. After fitting the tensor model (weighted least-squares approach), the TBSS pipeline applies nonlinear registration to match individual FA maps to MNI standard space (target = FMRIB58_FA standard-space image, study-specific mean FA and skeleton, FA threshold $=0.2$ ). A skeleton of white matter tracts is created from the mean FA image, and individual maps are finally mapped to this skeleton. Non-FA images (i.e., $\mathrm{AD}, \mathrm{RD}$, and $\mathrm{MD}$ ) are processed in the same manner by using the transformations obtained from the FA processing procedure. Because men and women differ in overall brain size
(Allen et al., 2002; Gong et al., 2009; Giedd et al., 2012), the total intracranial volume (TIV) was extracted from T1-weighted images for inclusion in the statistical analyses. Using the VBM8 toolbox (http://dbm. neuro.uni-jena.de/vbm/) for SPM8 (http://www.fil.ion.ucl.ac.uk/spm/), structural scans were segmented into gray and white matter, as well as CSF. The TIV was calculated as the sum of these three parameters.

To validate our findings, TBSS results were compared with whole tract diffusion parameters for right and left corticospinal tract (CST), forceps major (Fmajor), and forceps minor (Fminor) using probabilistic tractography. This was done with the FSL Diffusion Toolbox in individual space (Behrens et al., 2003) as reported previously (Hahn et al., 2014). Local diffusion parameters were computed with 5000 sample streamlines and two fiber directions per voxel (Behrens et al., 2007), which enables modeling of crossing fibers and tracking of nondominant pathways. Seed and target regions for right and left CST, Fmajor, and Fminor were delineated as described previously (Wakana et al., 2007). Reconstructed tracts were thresholded to remove spurious connections. Here, voxels exhibiting the lowest $5 \%$ of sample streamlines or areas with FA $<0.2$ were removed (Croxson et al., 2005). From the final tracts, average values of FA, MD, AD, and $\mathrm{RD}$ were extracted for each individual for additional statistical evaluation.

Statistical analysis. Voxelwise statistics of the skeletonized FA, MD, $\mathrm{AD}$, and $\mathrm{RD}$ data were performed using analysis of covariance (ANCOVA) with group as factor (four levels: FC, FtM, MtF, and MC). TIV was entered as covariate of no interest in the analysis because the relative contribution of partial volume effect-contaminated voxels may be different and systematically distort DTI metrics (Vos et al., 2011), given the expected differences in brain volumes between groups (see below). Significant results in the $F$ test served as a mask for voxels that were subjected to post hoc two-sample $t$ tests. To investigate whether the three sex steroid 
hormones $\left(\mathrm{E}_{2}, \mathrm{~T}\right.$, and $\left.\mathrm{P}_{4}\right)$ or sexual orientation explained group differences, the named variables were added as covariates of no interest within separate ANCOVA analyses. Finally, multiple regression analyses were performed to determine the effects of hormones and sexual orientation on diffusivity maps independent of group membership, i.e., with group in addition to TIV as factor of no interest. Separate models were calculated for each of the independent variables $\left(E_{2}, T, P_{4}\right.$, and sexual orientation). Because hormone values over the entire sample were non-normally distributed, they were transformed to ordinal scales based on ranks before inclusion in the analysis. Sexual orientation was entered into analyses in three different ways of coding: (1) as raw values of the Likert scale ( 1 for attraction toward females; 7 for attraction toward males); (2) as a spectrum from homosexuality (e.g., 1) to heterosexuality (e.g., 7) with reference to the raters' genetic sex; and (3) as a spectrum from homosexuality to heterosexuality with reference to the raters' gender identity. The statistical threshold was set at $p<0.05$ FWE corrected, using the threshold-free cluster enhancement method to define the clusters (Smith and Nichols, 2009). Voxels showing significant differences were assigned to white matter tracts using the DTI- 81 white matter atlas of the International Consortium for Human Brain Mapping as provided by the DiffeoMap software package (www.mristudio.org/wiki/user manual/diffeomap). Diffusivities based on tract-specific quantification for right and left CST, Fmajor, and Fminor were compared using ANOVA in SPSS. Separate models were calculated for each tract and diffusivity parameter, followed by post hoc pairwise comparisons and correction for multiple comparisons using the Bonferroni's procedure. Analyses were run with and without TIV as covariate of no interest. Separate correlation analyses were performed to examine the association between diffusivities and age and between volumetric data [gray matter volume (GMV), white matter volume (WMV), CSF, and TIV] and age for each group.

\section{Results}

\section{Group comparisons of TBSS measures}

Whole-brain TBSS analysis revealed widespread differences in MD, $\mathrm{AD}$, and $\mathrm{RD}$ maps between the investigated groups, whereas no significant voxels were found for FA maps. Differences in MD included virtually all white matter tracts. Post hoc pairwise comparisons revealed the transition $\mathrm{MC}<\mathrm{MtF}<\mathrm{FtM}<\mathrm{FC}$, with $\mathrm{MD}$ values and number of significant voxels increasing significantly (Figs. 1, 2). In other words, female biological sex and female gender identity were associated with increased MD. FCs had significantly higher MD values than FtM transsexuals in voxels within the right cerebral peduncle, bilateral internal and external capsule, right posterior corona radiate, right hippocampal cingulum, bilateral stria terminalis, right superior longitudinal fasciculus, body and splenium of corpus callosum, right frontal, superior, and postcentral blades, and bilateral parietal and temporal blades. When MD values in FCs were compared with MtF transsexuals, voxels corresponding to the above-named regions were complemented by a large number of additional regions (Fig. 1). This trend in increasing MD differences (both in terms of increased MD values and larger numbers of significant voxels) culminated in the comparison of FCs with MCs in which FCs had higher MD values in virtually all regions compared with MCs (Fig. 1). None of the investigated voxels showed significantly increased MD values in male biological sex or male gender identity compared with female biological sex or female gender identity. However, some brain regions showed differences only between biological sexes but not between different gender identities within the same biological sex, e.g., between FCs and MtF transsexuals but not between FCs and FtM transsexuals. This included voxels in the cerebellar peduncle and right CST (Fig. 2), as well as in bilateral medial lemniscus, splenium of corpus callosum, and left superior parietal blade.
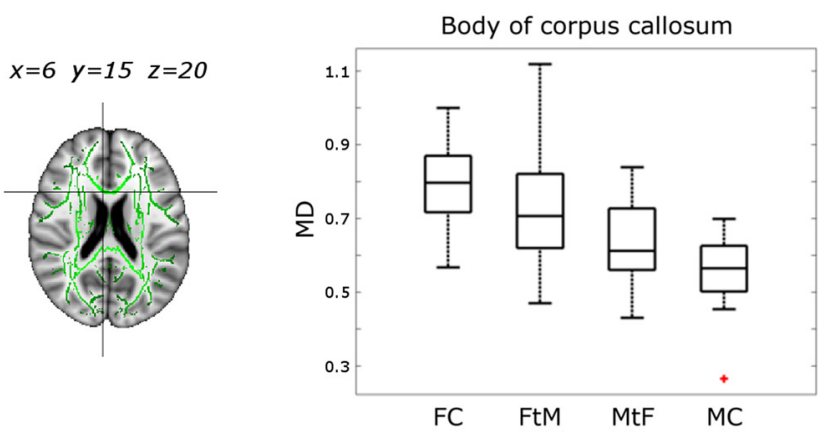

Superior frontal blade right
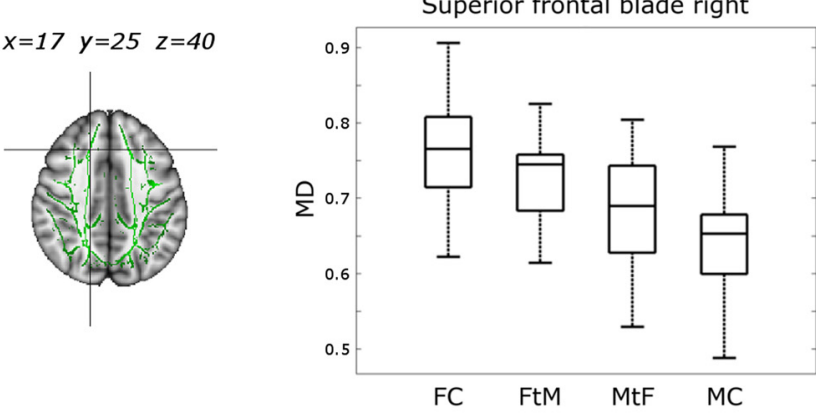

Corticospinal tract right
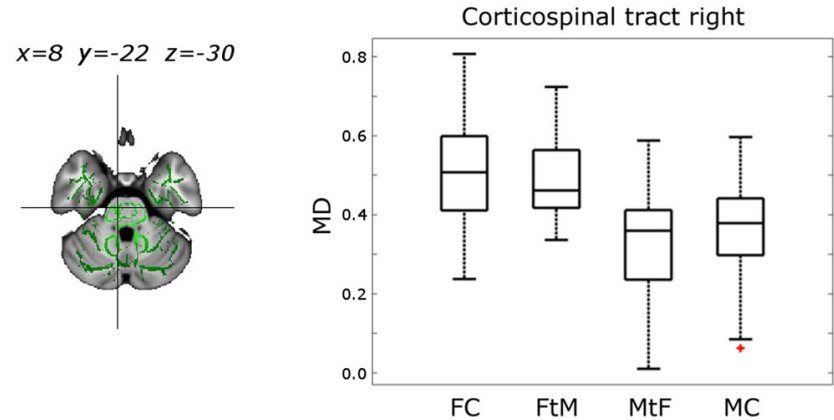

Figure 2. Box plots representing estimated $M D s\left(10^{-3} \mathrm{~mm}^{2} / \mathrm{s}\right.$, centered around global mean $)$ of the four study groups (FCs, MCs, FtM transsexuals, and MtF transsexuals). Values refer to regional MD corresponding to the crosshair depicted on the left axial template. Because results are corrected for TIV, values are mean centered. Locations are given in millimeters, MNI standard space. Values are derived from the ANCOVA model using TIV as the covariate of no interest. The transition MC-MtFFtM-FC in significantly increasing MD values becomes apparent in the body of corpus callosum (top row) and the right superior frontal blade (middle row; $p<0.05$, FWE corrected). In the right CST (bottom row), significant differences are observed between the two biological sexes (e.g., FC and $\mathrm{FtM}>\mathrm{MtF}$ and $\mathrm{MC}$ ), whereas no significant differences are seen between F(s and FtM transsexuals or between MtF transsexuals and MCs. Left is right.

To determine which of the eigenvalues provided the main source for differences in $\mathrm{MD}$, we performed pairwise comparisons for $\mathrm{AD}$ and $\mathrm{RD}$ maps. These analyses revealed that results in $\mathrm{MD}$ were mostly triggered by differences in $\mathrm{AD}$. $\mathrm{AD}$ values were highest in FCs, followed by FtM and MtF transsexuals, with MCs having significantly lowest values (Fig. 3). In contrast, RD maps showed only few regions responsible for the abovementioned transition from FCs to MCs, including voxels in the right superior longitudinal fasciculus and right middle frontal and right parietotemporal blades (Fig. 4). In voxels within the right anterior corona radiata and right superior frontal blade, MtF transsexuals had higher RD values than FtM transsexuals. In all other regions, female sex and gender identity had significantly higher values. Conducting the ANOVAs without correction for TIV did not change the main direction of group differences, i.e., the transition $\mathrm{FC}>\mathrm{FtM}>\mathrm{MtF}>\mathrm{MC}$ for $\mathrm{MD}$, as well as $\mathrm{AD}$ and $\mathrm{RD}$. 


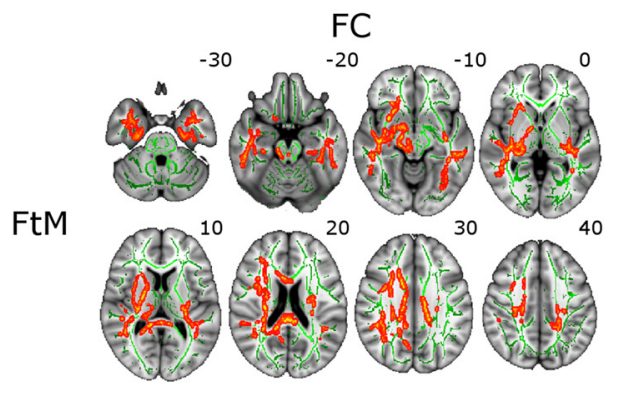

\section{AXIAL DIFFUSIVITY}
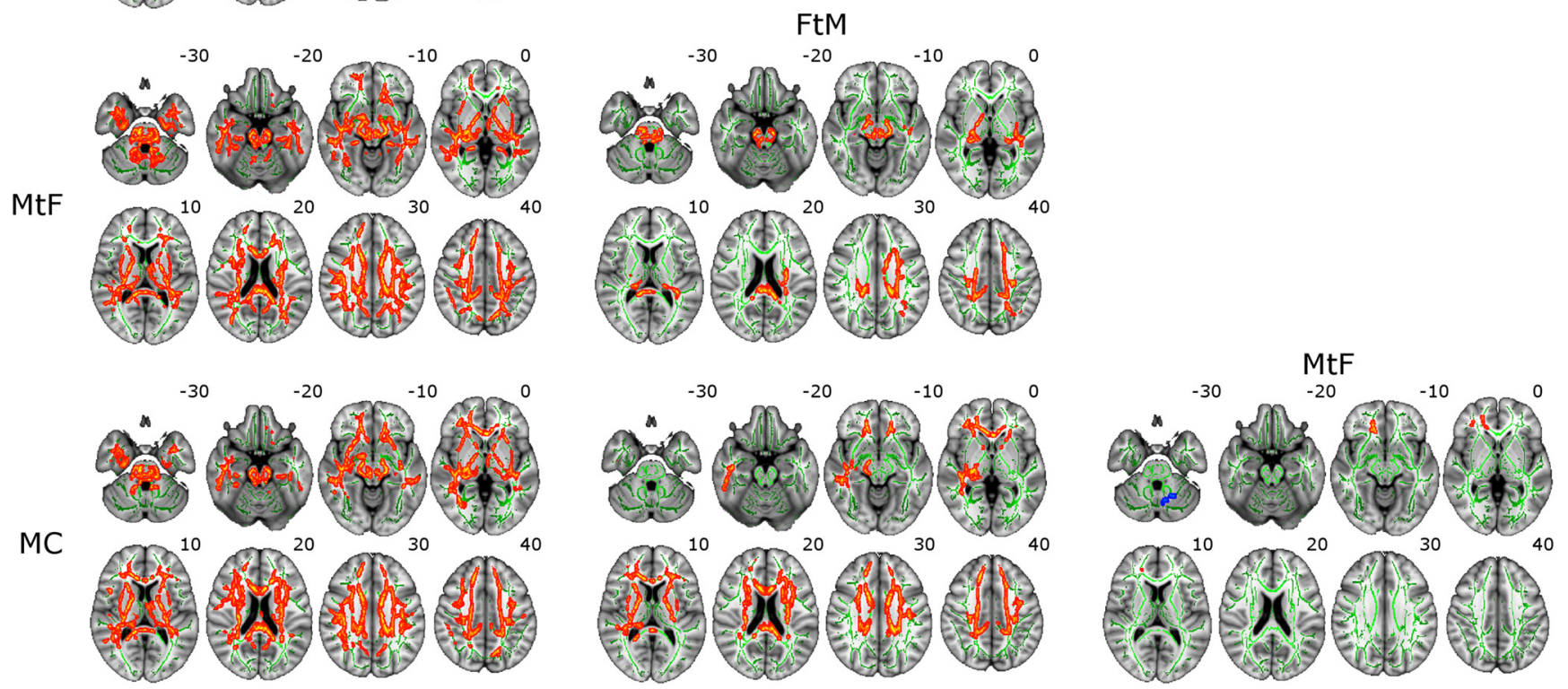

Figure 3. Effects of gender identity and sex on regional AD; see schema in Figure 1. Depicted are six comparisons, from top to bottom: $F C>F t M, F C>M t F, F C>M C$ (first column); FtM $>M t F$, $\mathrm{FtM}>\mathrm{MC}$ (second column); and MtF $>M C$ (third column), e. g. white matter tracts in red-yellow show significantly higher AD, and white matter tracts in blue- green show significantly lower AD in MtF transsexuals compared with MCs in the bottom right comparison ( $p<0.05$, FWE corrected). Left is right.

\section{Associations between TBSS measures and sex hormones}

To determine whether sex hormone status explained our findings, we first compared $\mathrm{E}_{2}, \mathrm{~T}$, and $\mathrm{P}_{4}$ plasma levels between groups and then associated them with diffusivity parameters. Group comparisons revealed an expected difference between genetic sexes, i.e., higher $\mathrm{E}_{2}$ and lower $\mathrm{T}$ levels in genetic females compared with males, but no significant difference between gender identities of the same biological sex (Table 1). Differences in diffusivity parameters between groups did not change when including sex steroid hormones as covariates of no interest.

Multiple regression analyses were performed to determine global hormone effects on the entire sample, independent of group membership, i.e., with group as variable of no interest. For $\mathrm{P}_{4}$, significant positive correlations for RD were observed in voxels within the body of the corpus callosum, the left superior corona radiate, and the right temporal blade. No significant effects were observed for $\mathrm{E}_{2}$ plasma levels. However, for $\mathrm{T}$, voxels in a variety of regions showed strong positive correlations with $\mathrm{MD}$, $\mathrm{AD}$, and $\mathrm{RD}$ maps. For $\mathrm{MD}$, regions included the middle cerebellar peduncle, bilateral CST, pontine crossing tract, bilateral fronto-occipital fasciculus, left external capsule, genu and body of corpus callosum, bilateral anterior corona radiate, and bilateral superior longitudinal fasciculus, as well as bilateral temporal, superior frontal, and parietal blades and bilateral precentral and postcentral blades. For AD, regions included the bilateral cerebral peduncle, left CST, the pontine crossing tract, internal capsule, body and splenium of the corpus callosum, bilateral inferior fronto-occipital fasciculus, right superior corona radiate, and bi- lateral temporal blades. For $\mathrm{RD}$, regions included the right cerebral peduncle, posterior thalamic radiation, bilateral posterior and inferior internal capsule, and splenium and body of corpus callosum, as well as bilateral temporal precentral and postcentral blades, right parietotemporal blades, and left occipital blades (Fig. 5).

\section{Associations between TBSS measures and sexual orientation}

Here, we investigated whether sexual orientation associates with diffusivity measures. No effects on our main findings were observed when sexual orientation was regressed out in the ANCOVA design. Moreover, there was no significant effect of sexual orientation on diffusivity parameters in the regression analysis including all subjects and using group as factor of no interest.

\section{Group comparisons using fiber tractography}

Similar to TBSS results, ANOVAs for right and left CST revealed significant differences between groups for $\mathrm{MD}$ and $\mathrm{AD}$. For RD, differences were significant for right CST and borderline significant for left CST (right CST: $M D, F_{(3,85)}=6.14, p=0.001 ; \mathrm{AD}$, $F_{(3,85)}=6.47, p=0.001$; RD: $F_{(3,85)}=3.57, p=0.02$; left CST: $\mathrm{MD}, F_{(3,85)}=5.04, p=0.003 ; \mathrm{AD}, F_{(3,85)}=6.62, p<0.001 ; \mathrm{RD}$, $\left.F_{(3,85)}=2.63, p=0.056\right)$. No group differences were observed for FA. Data further confirmed TBSS results, showing the transition $\mathrm{FC}>\mathrm{FtM}>\mathrm{MtF}>\mathrm{MC}$ in $\mathrm{MD}, \mathrm{AD}$, and $\mathrm{RD}$ (for means $\pm \mathrm{SDs}$, see Table 2). This transition also accounted for significant results in post hoc pairwise comparisons, showing most significant differences between FCs and MCs (for other significant comparisons, see Table 2; all $p$ vales Bonferroni's corrected). Including 


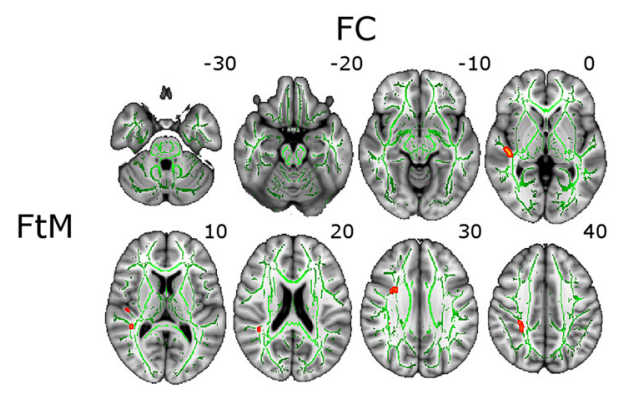

\section{RADIAL DIFFUSIVITY}
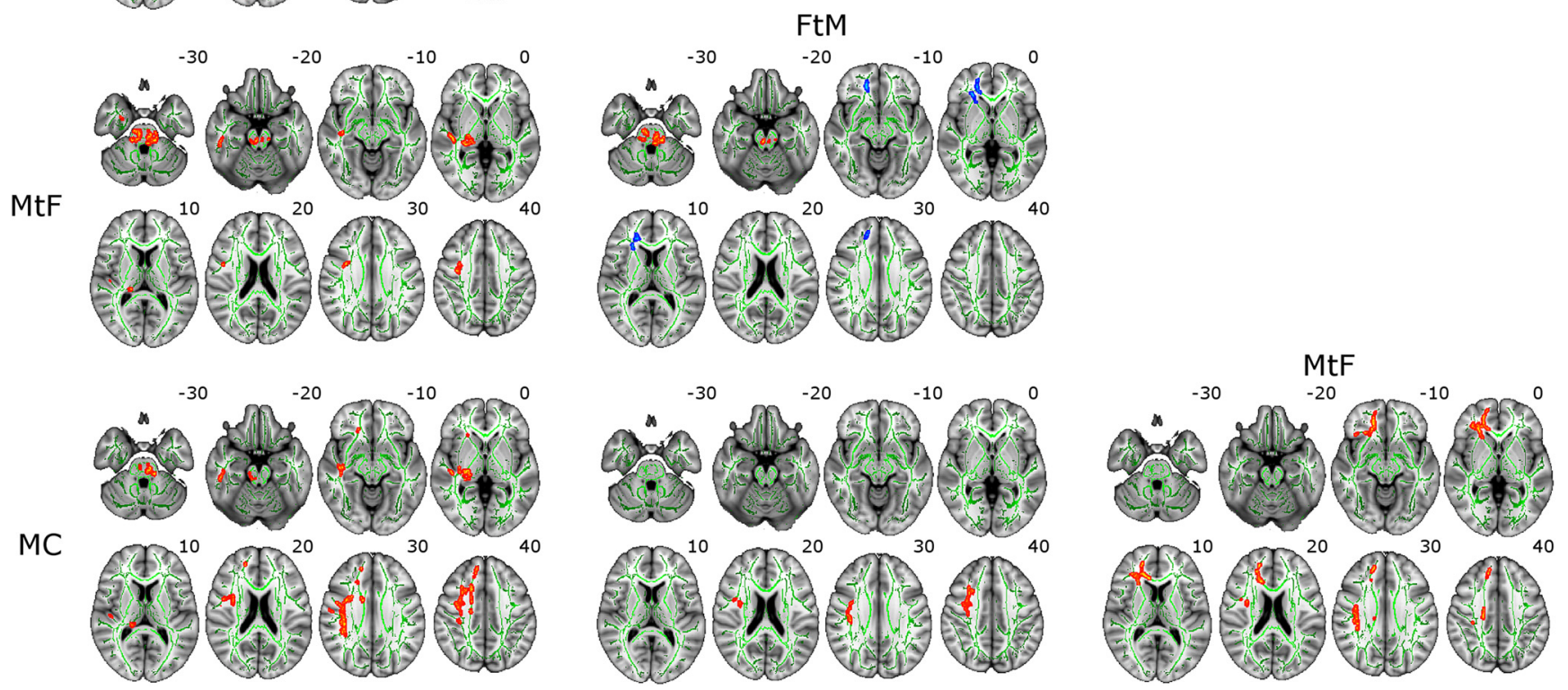

Figure 4. Effects of gender identity and sex on regional RD; see schema in Figure 1. Depicted are six comparisons, from top to bottom: $F C>F t M, F C>M t F, F C>M C$ (first column); FtM $>$ MtF, $\mathrm{FtM}>\mathrm{MC}$ (second column); and MtF $>M C$ (third column), e.g., white matter tracts in red-yellow show significantly higher RD, and white matter tracts in blue- green show significantly lower RD in FtM transsexuals compared with MtF transsexuals in the first comparison of the second column ( $p<0.05$, FWE corrected). Left is right.

TIV as covariate of no interest did not change the significance of the results. However, group comparisons for Fmajor and Fminor confirmed only in part the TBSS results. Although for Fmajor FC still had highest values compared with other groups for $\mathrm{MD}, \mathrm{AD}$, and $\mathrm{RD}$, group differences did not reach significance (Table 2). For Fminor, group differences were significant for $\operatorname{MD}\left(F_{(3,85)}=\right.$ $4.10, p=0.009), \operatorname{RD}\left(F_{(3,85)}=3.59, p=0.017\right)$, and FA $\left(F_{(3,85)}=\right.$ $2.88, p=0.041)$, but here, post hoc pairwise comparisons revealed that $\mathrm{MtF}$ transsexuals had higher values compared with FtM transsexuals (for MD and RD), whereas for FA, FtM transsexuals had higher values than $\mathrm{MtF}$ transsexuals $(p<0.05$, Bonferroni's corrected).

\section{Group comparisons of GMV, WMV, CSF, and TIV}

Separate ANOVAs for GMV, WMV, CSF, and TIV revealed significant differences between the four groups, with larger volumes found in genetic males than genetic females. Interestingly, except for CSF, volumes exhibited also a transition: $\mathrm{FC}<\mathrm{FtM}<\mathrm{MtF}<$ $\mathrm{MC}$ (for means \pm SDs, see Table 1). Post hoc pairwise comparisons revealed significantly larger volumes in MCs compared with FCs and FtM transsexuals and in MtF transsexuals compared with FCs for all volumes ( $p<0.05$, Bonferroni's corrected). Other comparisons showed only a trend $(\mathrm{MtF}>$ FtM for GMV; FtM $>$ FC for GMV, WMV, and TIV) or no difference (MC > $\mathrm{MtF}$ for GMV, WMV, CSF, and TIV; FtM > FC for CSF).

\section{Associations of diffusivities and volumetries with age}

Pearson's correlations revealed negative associations between AD and age in CST bilaterally and between RD and age in left CST and Fminor $(p<0.05$, corrected; for separate correlations per group and uncorrected values, see Table 3 and Fig. 6). Also, MD showed negative correlations with age in left CST, whereas FA was negatively correlated in Fminor $(p<0.05$, corrected). GMV was negatively correlated with age ( $p<0.05$, uncorrected), whereas CSF was positively correlated with age $(p<0.05$, corrected).

\section{Discussion}

The results of this study show that white matter microstructure in FtM and MtF transsexuals falls halfway between that of FCs and MCs. Females with a female gender identity (FCs) had highest MDs, followed by females with a male gender identity (FtM transsexuals). Further decreased values were found in males with a female gender identity (MtF transsexuals), followed by males with a male gender identity (MCs) having the lowest MD. Differentiating the contribution of the different eigenvalues revealed that predominantly AD accounted for MD differences. However, increased values in RD in female sex/gender identity compared with male sex/gender identity also contributed to MD results, because no group differences were observed for FA maps. This can be best appreciated when looking at how parameter maps FA, $\mathrm{MD}, \mathrm{AD}$, and $\mathrm{RD}$ are calculated from the principal eigenvalues $\lambda_{1}, \lambda_{2}$, and $\lambda_{3}$ (see equations above). FA increases as disparity between the three eigenvalues increases, whereas MD rises with the sum of eigenvalues. Furthermore, examination of the equations also explains why FA (or MD) may be similar between groups, although eigenvalues can undergo significant changes. Therefore, it is regarded as essential that all eigenvalues, or at least 


\section{TESTOSTERONE}
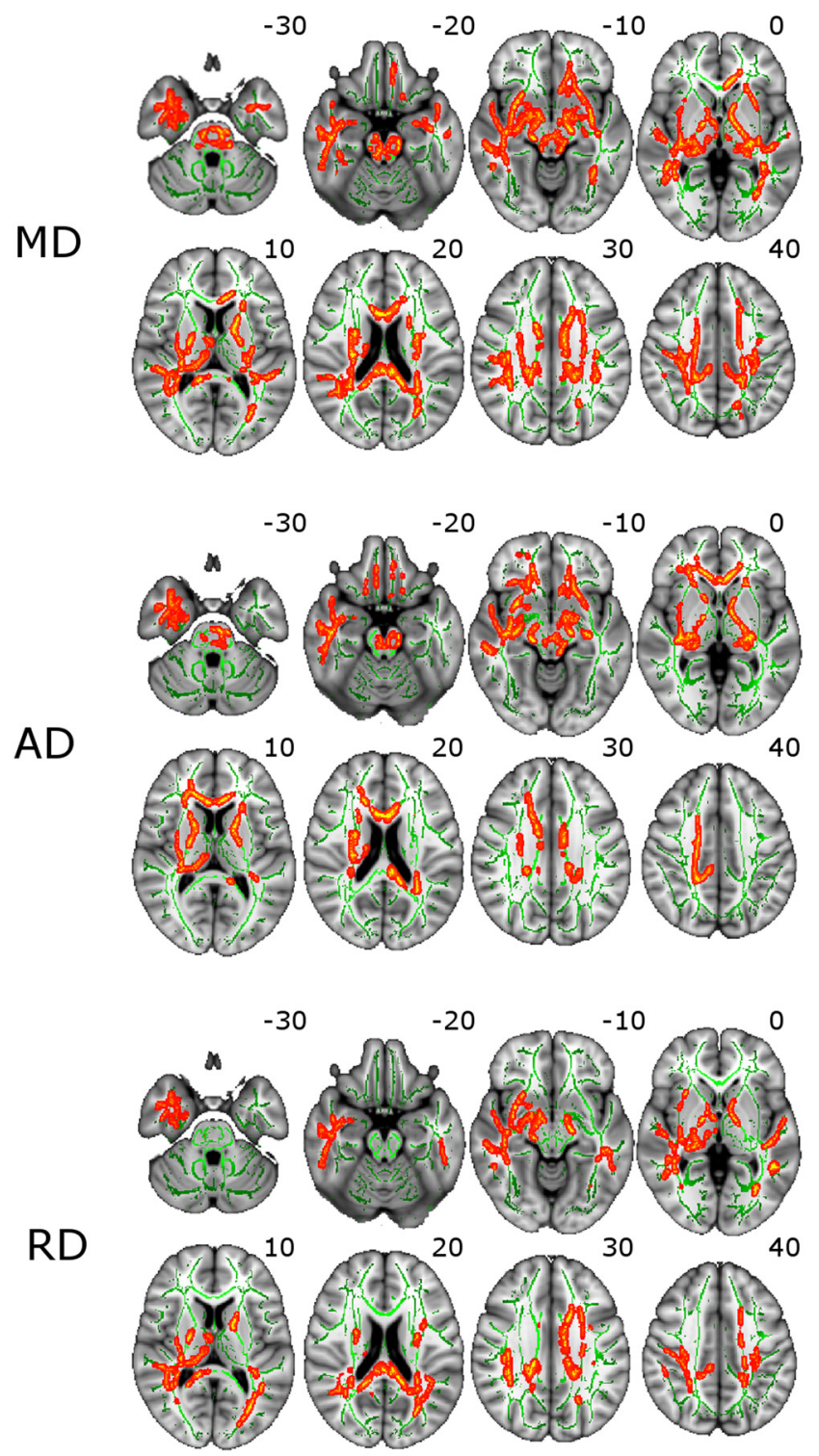

Figure 5. Positive association between $T$ plasma levels and regional $M D, A D$, and $R D$, i.e., white matter tracts in red-yellow show significant positive associations ( $p<0.05$, FWE corrected). Data are based on a multiple regression analysis of the entire sample using group as variable of no interest. Left is right.

$\mathrm{AD}$ and $\mathrm{RD}$, are reported in addition to $\mathrm{FA}$ and $\mathrm{MD}$ (Beaulieu, 2009). However, only few DTI studies meet these demands.

In our study, we find robust differences between investigated groups in $\mathrm{MD}, \mathrm{AD}$, and $\mathrm{RD}$ indicating that biological sex and gender identity both contribute to observed group differences. Moreover, the high positive correlation with adult plasma T levels (controlling for group membership) indicates that group differences cannot be explained by peripheral sex hormone plasma levels. As expected, biological males (MCs and MtF transsexuals) had higher T levels than biological females (FCs and FtM transsexuals), whereas group differences in diffusivity values showed the transition FC $>$ FtM $>$ MtF $>$ MC. Furthermore, group differences were not explained by differences in sexual orientation, narrowing potential determinants for differences in diffusivity parameters to biological sex and gender identity.
Table 2. Group differences of diffusivities based on individual fiber tractography

\begin{tabular}{lllll}
\hline & FCs & FtM transsexuals & MtF transsexuals & MCs \\
\hline$n$ & 23 & 23 & 21 & 22 \\
AD (10 $\left.{ }^{-3} \mathrm{~mm}^{2} / \mathrm{s}\right)$ & & & & \\
$\quad$ Right CST & $1.12 \pm 0.05^{c, d}$ & $1.09 \pm 0.05$ & $1.08 \pm 0.05^{a}$ & $1.06 \pm 0.05^{a}$ \\
$\quad$ Left CST & $1.09 \pm 0.05^{c, d}$ & $1.06 \pm 0.06$ & $1.04 \pm 0.05^{a}$ & $1.03 \pm 0.05^{a}$ \\
$\quad$ Fmajor & $1.35 \pm 0.09$ & $1.32 \pm 0.07$ & $1.29 \pm 0.08$ & $1.32 \pm 0.10$ \\
$\quad$ Fminor & $1.31 \pm 0.07$ & $1.30 \pm 0.09$ & $1.32 \pm 0.07$ & $1.30 \pm 0.08$ \\
RD (10 $\left.{ }^{-3} \mathrm{~mm}^{2} / \mathrm{s}\right)$ & & & & \\
$\quad$ Right CST & $0.46 \pm 0.03^{d}$ & $0.45 \pm 0.03$ & $0.45 \pm 0.03$ & $0.43 \pm 0.02^{a}$ \\
$\quad$ Left CST & $0.44 \pm 0.03$ & $0.43 \pm 0.03$ & $0.42 \pm 0.03$ & $0.42 \pm 0.03$ \\
$\quad$ Fmajor & $0.47 \pm 0.06$ & $0.46 \pm 0.04$ & $0.47 \pm 0.05$ & $0.46 \pm 0.07$ \\
$\quad$ Fminor & $0.37 \pm 0.08$ & $0.35 \pm 0.06^{c}$ & $0.42 \pm 0.08^{b}$ & $0.38 \pm 0.07$ \\
MD (10 $\left.{ }^{-3} \mathrm{~mm}^{2} / \mathrm{s}\right)$ & & & & \\
$\quad$ Right CST & $0.68 \pm 0.04^{d}$ & $0.67 \pm 0.03^{d}$ & $0.66 \pm 0.03$ & $0.64 \pm 0.03^{a, b}$ \\
$\quad$ Left CST & $0.66 \pm 0.04^{c, d}$ & $0.64 \pm 0.04$ & $0.63 \pm 0.03^{a}$ & $0.62 \pm 0.03^{a}$ \\
$\quad$ Fmajor & $0.77 \pm 0.06$ & $0.75 \pm 0.05$ & $0.74 \pm 0.05$ & $0.75 \pm 0.07$ \\
$\quad$ Fminor & $0.68 \pm 0.05$ & $0.66 \pm 0.04^{c}$ & $0.72 \pm 0.05^{b}$ & $0.68 \pm 0.06$ \\
FA & & & & \\
$\quad$ Right CST & $0.54 \pm 0.02$ & $0.54 \pm 0.02$ & $0.54 \pm 0.03$ & $0.55 \pm 0.02$ \\
$\quad$ Left CST & $0.55 \pm 0.02$ & $0.55 \pm 0.02$ & $0.55 \pm 0.03$ & $0.55 \pm 0.02$ \\
$\quad$ Fmajor & $0.61 \pm 0.03$ & $0.61 \pm 0.03$ & $0.59 \pm 0.04$ & $0.61 \pm 0.04$ \\
$\quad$ Fminor & $0.67 \pm 0.07$ & $0.69 \pm 0.06^{c}$ & $0.63 \pm 0.07^{b}$ & $0.66 \pm 0.07$ \\
\hline
\end{tabular}

Group comparisons were done using ANOVA and post hoc pairwise t test for AD, RD, MD, and FA.

${ }^{a}$ Significant difference to $\mathrm{FC} s, p<0.05$, Bonferroni's corrected.

${ }^{b}$ Significant difference to FtM transsexuals, $p<0.05$, Bonferroni's corrected.

'Significant difference to MtF transsexuals, $p<0.05$, Bonferroni's corrected.

${ }^{d}$ Significant difference to MCs, $p<0.05$, Bonferroni's corrected.

Table 3. Correlations of diffusivities and volumetric data with age

\begin{tabular}{lccccc}
\hline & FCs & FtM transsexuals & MtF transsexuals & MCs & All \\
\hline$n$ & 23 & 23 & 21 & 22 & 89 \\
AD $\left(10^{-3} \mathrm{~mm}^{2} / \mathrm{s}\right)$ & & & & & \\
$\quad$ Right CST & -0.410 & $-0.416^{\#}$ & -0.434 & -0.238 & $-0.337^{*}$ \\
$\quad$ Left CST & -0.347 & -0.331 & $-0.712^{*}$ & -0.188 & $-0.396^{*}$ \\
Fmajor & -0.110 & 0.129 & -0.294 & $-0.631^{*}$ & $-0.251^{\#}$ \\
$\quad$ Fminor & -0.179 & -0.023 & $-0.494^{\#}$ & -0.099 & -0.140 \\
RD (10 $\left.{ }^{-3} \mathrm{~mm}^{2} / \mathrm{s}\right)$ & & & & & \\
Right CST & $-0.581^{\#}$ & $-0.416^{\#}$ & 0.021 & 0.010 & -0.206 \\
Left CST & $-0.572^{\#}$ & -0.298 & $-0.450^{\#}$ & 0.001 & $-0.347^{*}$ \\
Fmajor & 0.021 & 0.304 & 0.002 & $-0.609^{\#}$ & -0.044 \\
$\quad$ Fminor & 0.247 & $0.500^{\#}$ & 0.245 & 0.215 & $0.347^{*}$ \\
MD & & & & & \\
Right CST & $-0.54^{\#}$ & $-0.466^{\#}$ & -0.228 & -0.138 & $-0.304^{\#}$ \\
Left CST & $-0.501^{\#}$ & -0.335 & $-0.648^{*}$ & -0.098 & $-0.400^{*}$ \\
Fmajor & -0.040 & 0.253 & -0.148 & $-0.658^{*}$ & -0.150 \\
$\quad$ Fminor & 0.162 & $0.431^{\#}$ & 0.020 & 0.136 & $0.254^{\#}$ \\
FA & & & & & \\
Right CST & $0.481^{\#}$ & 0.246 & -0.271 & -0.078 & 0.003 \\
Left CST & $0.570^{\#}$ & 0.138 & 0.073 & -0.031 & 0.159 \\
Fmajor & -0.066 & -0.202 & -0.183 & 0.374 & -0.251 \\
Fminor & -0.260 & $-0.455^{\#}$ & -0.323 & -0.245 & $-0.363^{*}$ \\
Volumetric data & & & & & \\
GMV & $-0.520^{\#}$ & $-0.517^{\#}$ & -0.034 & $-0.534^{\#}$ & $-0.275^{\#}$ \\
WMV & 0.055 & 0.135 & $0.648^{*}$ & -0.229 & 0.205 \\
CSF & 0.267 & 0.233 & $0.739^{*}$ & -0.190 & $0.341^{*}$ \\
TIV & -0.245 & -0.131 & $0.529^{\#}$ & -0.373 & 0.051 \\
\hline
\end{tabular}

Pearson's product moment correlations between age and diffusivities based on individual tractography. ${ }^{*} p<0.05$ corrected $(p=0.0025) ;{ }^{\#} p<0.05$, uncorrected

$\mathrm{T}$ in the womb and early neonatal life plays a decisive role in sexual brain differentiation, which is believed to underlie a subject's gender identity (Swaab and Garcia-Falgueras, 2009). This organizational effect produces permanent changes in the cellular organization of brain tissue that occurs during critical periods when differences in serum $\mathrm{T}$ are highest between sexes (Auyeung 

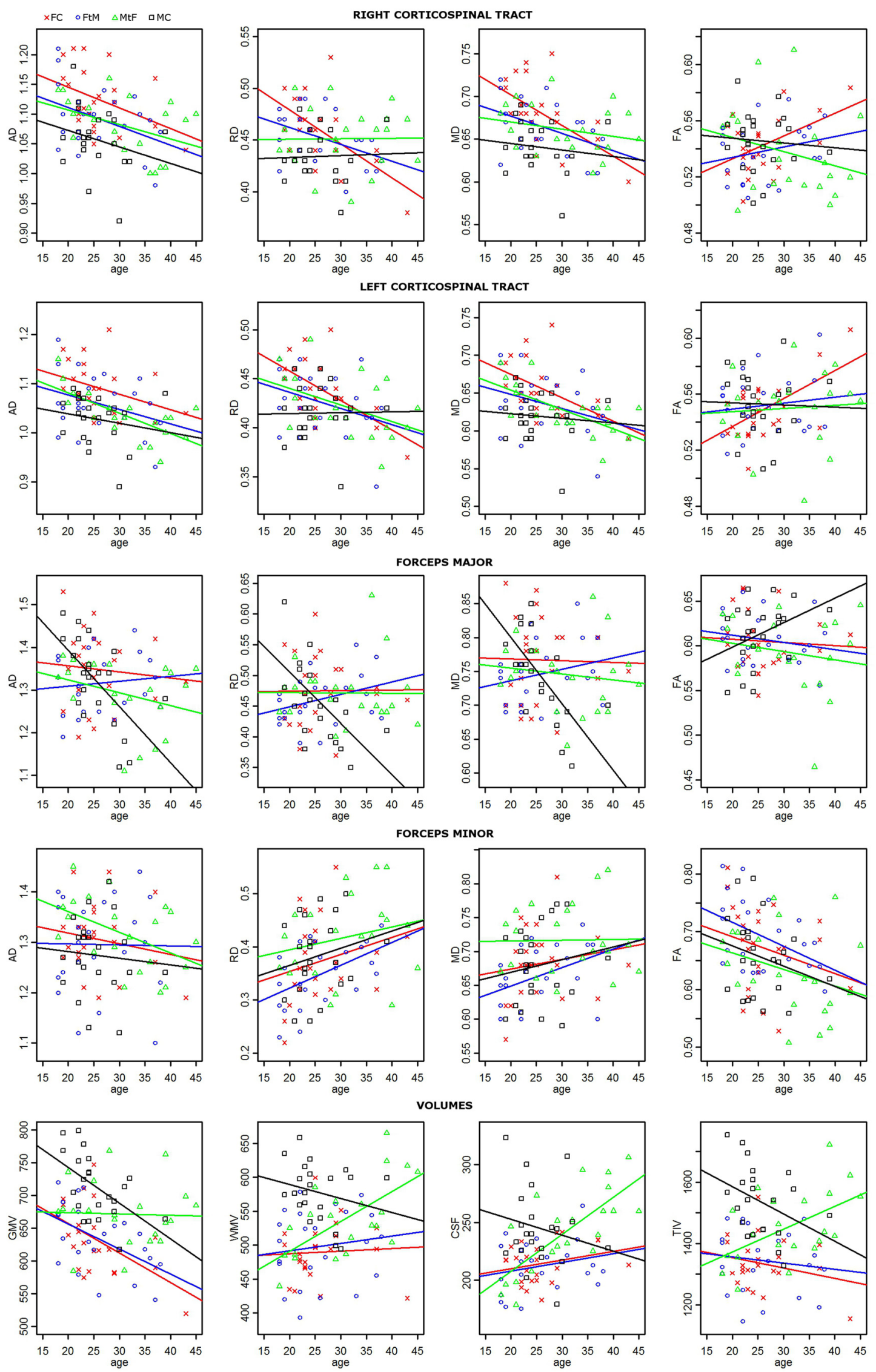

Figure 6. Scatter plots depicting the association between diffusivities and age in four major tracts, in right and left CST and Fmajor and Fminor. FCs, Red crosses; FtM transsexuals, blue circles; MtF transsexuals, green triangles; MCs, black squares. For correlations, see Table 3. 
et al., 2013). Functional and structural MRI studies in 8- to 11year-old children found that fetal $\mathrm{T}$ predicted neural response to valenced facial cues in reward-related regions, such as nucleus accumbens, caudate, and putamen (Lombardo et al., 2012b). Furthermore, fetal T was shown to predict GMV in the temporoparietal junction, superior temporal sulcus, orbitofrontal cortex, and planum temporale (Lombardo et al., 2012a), as well as white matter asymmetry in corpus callosum size (Chura et al., 2010). T thereby acts either directly on developing neurons or via local conversion to estrogen by the enzyme aromatase, and estrogen then masculinizes certain brain areas, regulates synapse formation, and acts as a neurotrophic factor (Li and Shen, 2005; McCarthy, 2008; Savic et al., 2010).

However, studies indicate that sexual differentiation of the brain also occurs before the onset of hormone production (Lentini et al., 2013). Furthermore, organizational effects of fetal hormones may depend on the chromosomal sex (Carrer and Cambiasso, 2002). Several studies on growth and differentiation of neurons in vitro indicated sexual differences in response to $\mathrm{E}_{2}$ : $\mathrm{E}_{2}$ treatment induced earlier axon differentiation in neurons from females but not from males (Díaz et al., 1992), whereas axon growth during $\mathrm{E}_{2}$ treatment was increased in neurons from males but not from females (Cambiasso et al., 2000). In light of these findings, we can speculate on a sex-dependent differential effect of fetal $\mathrm{T}$ on white matter microstructure, which explains the group differences found in the present study. Unfortunately, however, this could not be tested directly in the current study because information on fetal $\mathrm{T}$ levels was not available.

Our results indicate that organizational effects early in brain development seem to oppose the effects of T later in life. Whereas group differences showed the transition $\mathrm{FC}>\mathrm{FtM}>\mathrm{MtF}>\mathrm{MC}$, indicating an inverse relationship between fetal $\mathrm{T}$ and $\mathrm{MD}$, adult plasma T levels showed a strong positive correlation with MD. Indeed, cell culture studies indicate that gonadal steroid hormone effects on neuritogenesis are age dependent and region specific (Carrer and Cambiasso, 2002; McCarthy, 2008). Furthermore, DTI studies corroborate relatively higher FA and $\mathrm{AD}$ in males and higher $\mathrm{MD}$ and $\mathrm{RD}$ in females in many white matter tracts (Hsu et al., 2008; Inano et al., 2011; Menzler et al., 2011), which seems to contradict recent data indicating strong positive correlations between RD and adult T levels in males (Peper et al., 2013). Given the highly dynamic nature of the effects of sex hormones on cellular growth and differentiation, generalizations about their influence should thus be treated with great caution.

Our results strengthen the notion of an observable and measurable biological basis of gender identity and put gender dysphoria into the realm of human physiological variation. Nevertheless, our results diverge from the DTI studies by Rametti et al. (2011a,b) who reported greater FA in MCs than in FCs, with $\mathrm{MtF}$ and FtM transsexuals lying between both control groups. However, the authors restricted their analysis to FA, whereas MD or eigenvalues were not reported. Second, they did not account for the modulating effects of plasma hormone levels or sexual orientation, as done in our study. However, we show that neither the sex steroid hormones nor sexual orientation explain our observed group differences. Third, in addition to TBSS, we performed probabilistic tractography, which confirmed our findings of the transition $\mathrm{FC}>\mathrm{FtM}>\mathrm{MtF}>\mathrm{MC}$ in right and left CST. Interestingly, however, for voxels within the CST, the TBSS approach showed differences only between biological sexes but not gender identities within the same biological sex. Furthermore, also in Fmajor and Fminor, MD parameters did only in part reflect regional TBSS findings. This is not surprising given the fact that TBSS results in clusters of voxels did not cover entire tracts (Figs. 1, 3, 4). Finally, several recent DTI studies showed that MD increases with age, indicating that age may have had a modulating role in our study (Hsu et al., 2008; Inano et al., 2011). However, if age explained observed group differences, then FCs should have been oldest, followed by FtM and MtF transsexuals, whereas MCs should have been youngest. This was not the case. In our study, $\mathrm{MtF}$ transsexuals were on average older than the three other groups. However, MD seemed to decrease in the CST, whereas it increased in Fminor. Age was also negatively correlated with AD, indicating that group differences may partly reflect the age mismatch between groups. Hence, our data indicate that a person's biological sex and gender identity are, at least in part, reflected in the brain's white matter microstructure of that very person.

Several possible limitations of this study should be noted. First, crossing fibers are a major problem in the interpretation of DTI results (Behrens et al., 2007; Jbabdi et al., 2010). In fact, the diffusion tensor model is inadequate in the many regions in which multiple fiber orientations contribute to the signal measured for the same voxel (Tournier et al., 2011). Hence, it remains open, to which neurobiological property, including the crossing of fiber bundles, axonal directional coherence, axonal density, or axon size, our results can be attributed. Second, our interpretation of study results mainly focused on a potential hormonal influence in the womb and early neonatal life. So far, we did not touch on genetic determinants of gender, although co-occurrence among twins, brother-sister pairs, and father-son pairs point toward transsexuality as heritable (Hyde and Kenna, 1977; Green, 2000). In a sample of MtF transsexuals, a study showed that a CAG repeat length polymorphism in the androgen receptor (AR) gene was significantly associated with transsexuality (Hare et al., 2009). MtF transsexuals had longer CAG repeats than MCs, indicating less effective $\mathrm{T}$ signaling in the former, which may be interpreted as less masculinization during early brain development. Interestingly, the same polymorphism has been linked to axonal caliber in a large sample of developing adolescents (Perrin et al., 2009). The study showed that T-related increases in white matter growth were stronger in males with lower number of CAG repeats in the AR gene. Therefore, we cannot exclude the possibility of a genetic component that explains parts of our results. Finally, because the exact onset of gender dysphoria, the severity, and other measures of transsexuality were not acquired in this study, the evaluation of potential associations with the obtained DTI metrics will remain an issue for future research.

\section{Conclusion}

The results of this study show that the white matter microstructure in FtM and MtF transsexuals falls halfway between that of FCs and MCs. Our data harmonize with the hypothesis that fiber tract development is influenced by the hormonal environment during late prenatal and early postnatal brain development that is proposed to determine gender identity.

\section{References}

Allen JS, Damasio H, Grabowski TJ (2002) Normal neuroanatomical variation in the human brain: an MRI-volumetric study. Am J Phys Anthropol 118:341-358. CrossRef Medline

American Psychiatric Association (2000) Diagnostic and statistical manual of mental disorders DSM-IV-TR, Ed 4 (text revision). Washington, DC: American Psychiatric Press.

Auyeung B, Lombardo MV, Baron-Cohen S (2013) Prenatal and postnatal hormone effects on the human brain and cognition. Pflugers Arch 465: 557-571. CrossRef Medline

Bao AM, Swaab DF (2011) Sexual differentiation of the human brain: rela- 
tion to gender identity, sexual orientation and neuropsychiatric disorders. Front Neuroendocrinol 32:214-226. CrossRef Medline

Beaulieu C (2009) The biological basis of diffusion anisotropy. In: Diffusion MRI (Johansen-Berg H, Behrens TE, eds), pp 106-127. London: Elsevier.

Behrens TE, Woolrich MW, Jenkinson M, Johansen-Berg H, Nunes RG, Clare S, Matthews PM, Brady JM, Smith SM (2003) Characterization and propagation of uncertainty in diffusion-weighted MR imaging. Magn Reson Med 50:1077-1088. CrossRef Medline

Behrens TE, Berg HJ, Jbabdi S, Rushworth MF, Woolrich MW (2007) Probabilistic diffusion tractography with multiple fibre orientations: what can we gain? Neuroimage 34:144-155. CrossRef Medline

Cambiasso MJ, Colombo JA, Carrer HF (2000) Differential effect of oestradiol and astroglia-conditioned media on the growth of hypothalamic neurons from male and female rat brains. Eur J Neurosci 12:2291-2298. CrossRef Medline

Carrer HF, Cambiasso MJ (2002) Sexual differentiation of the brain: genes, estrogen, and neurotrophic factors. Cell Mol Neurobiol 22:479-500. CrossRef Medline

Chou KH, Cheng Y, Chen IY, Lin CP, Chu WC (2011) Sex-linked white matter microstructure of the social and analytic brain. Neuroimage 54: 725-733. CrossRef Medline

Chura LR, Lombardo MV, Ashwin E, Auyeung B, Chakrabarti B, Bullmore ET, Baron-Cohen S (2010) Organizational effects of fetal testosterone on human corpus callosum size and asymmetry. Psychoneuroendocrinology 35:122-132. CrossRef Medline

Croxson PL, Johansen-Berg H, Behrens TE, Robson MD, Pinsk MA, Gross CG, Richter W, Richter MC, Kastner S, Rushworth MF (2005) Quantitative investigation of connections of the prefrontal cortex in the human and macaque using probabilistic diffusion tractography. J Neurosci 25: 8854-8866. CrossRef Medline

De Cuypere G, Janes C, Rubens R (1995) Psychosocial functioning of transsexuals in Belgium. Acta Psychiatr Scand 91:180-184. CrossRef Medline

Díaz H, Lorenzo A, Carrer HF, Cáceres A (1992) Time lapse study of neurite growth in hypothalamic dissociated neurons in culture: sex differences and estrogen effects. J Neurosci Res 33:266-281. CrossRef Medline

Giedd JN, Raznahan A, Mills KL, Lenroot RK (2012) Review: magnetic resonance imaging of male/female differences in human adolescent brain anatomy. Biol Sex Differ 3:19. CrossRef Medline

Gong G, Rosa-Neto P, Carbonell F, Chen ZJ, He Y, Evans AC (2009) Ageand gender-related differences in the cortical anatomical network. J Neurosci 29:15684-15693. CrossRef Medline

Green R (2000) Family cooccurrence of "gender dysphoria": ten sibling or parent-child pairs. Arch Sex Behav 29:499-507. CrossRef Medline

Hahn A, Kranz GS, Kublbock M, Kaufmann U, Ganger S, Hummer A, Seiger R, Spies M, Winkler D, Kasper S, Windischberger C, Swaab DF, Lanzenberger R (2014) Structural connectivity networks in transgender people. Cereb Cortex. Advance online publication. Retrieved October 7, 2014. doi:10.1093/cercor/bhu194. CrossRef Medline

Hare L, Bernard P, Sánchez FJ, Baird PN, Vilain E, Kennedy T, Harley VR (2009) Androgen receptor repeat length polymorphism associated with male-tofemale transsexualism. Biol Psychiatry 65:93-96. CrossRef Medline

Herting MM, Maxwell EC, Irvine C, Nagel BJ (2012) The impact of sex, puberty, and hormones on white matter microstructure in adolescents. Cereb Cortex 22: 1979-1992. CrossRef Medline

Hsu JL, Leemans A, Bai CH, Lee CH, Tsai YF, Chiu HC, Chen WH (2008) Gender differences and age-related white matter changes of the human brain: a diffusion tensor imaging study. Neuroimage 39:566-577. CrossRef Medline

Hyde C, Kenna JC (1977) A male MZ twin pair, concordant for transsexualism, discordant for schizophrenia. Acta Psychiatr Scand 56:265-275. CrossRef Medline

Inano S, Takao H, Hayashi N, Abe O, Ohtomo K (2011) Effects of age and gender on white matter integrity. AJNR Am J Neuroradiol 32:2103-2109. CrossRef Medline

Jbabdi S, Behrens TE, Smith SM (2010) Crossing fibres in tract-based spatial statistics. Neuroimage 49:249-256. CrossRef Medline

Johansen-Berg H, Behrens TE, eds (2009) Diffusion MRI. San Diego: Elsevier.

Klein F, Sepekoff B, Wolf TJ (1985) Sexual orientation: a multi-variable dynamic process. J Homosex 11:35-49. CrossRef Medline
Kranz GS, Hahn A, Baldinger P, Haeusler D, Philippe C, Kaufmann U, Wadsak W, Savli M, Hoeflich A, Kraus C, Vanicek T, Mitterhauser M, Kasper S, Lanzenberger R (2014) Cerebral serotonin transporter asymmetry in females, males and male-to-female transsexuals measured by PET in vivo. Brain Struct Funct 219:171-183. CrossRef Medline

Lentini E, Kasahara M, Arver S, Savic I (2013) Sex differences in the human brain and the impact of sex chromosomes and sex hormones. Cereb Cortex 23:2322-2336. CrossRef Medline

Li R, Shen Y (2005) Estrogen and brain: synthesis, function and diseases. Front Biosci 10:257-267. CrossRef Medline

Lombardo MV, Ashwin E, Auyeung B, Chakrabarti B, Taylor K, Hackett G, Bullmore ET, Baron-Cohen S (2012a) Fetal testosterone influences sexually dimorphic gray matter in the human brain. J Neurosci 32:674-680. CrossRef Medline

Lombardo MV, Ashwin E, Auyeung B, Chakrabarti B, Lai MC, Taylor K, Hackett G, Bullmore ET, Baron-Cohen S (2012b) Fetal programming effects of testosterone on the reward system and behavioral approach tendencies in humans. Biol Psychiatry 72:839-847. CrossRef Medline

McCarthy MM (2008) Estradiol and the developing brain. Physiol Rev 88: 91-124. CrossRef Medline

Menzler K, Belke M, Wehrmann E, Krakow K, Lengler U, Jansen A, Hamer HM, Oertel WH, Rosenow F, Knake S (2011) Men and women are different: diffusion tensor imaging reveals sexual dimorphism in the microstructure of the thalamus, corpus callosum and cingulum. Neuroimage 54:2557-2562. CrossRef Medline

Peper JS, Mandl RC, Braams BR, de Water E, Heijboer AC, Koolschijn PC, Crone EA (2013) Delay discounting and frontostriatal fiber tracts: a combined DTI and MTR study on impulsive choices in healthy young adults. Cereb Cortex 23:1695-1702. CrossRef Medline

Perrin JS, Leonard G, Perron M, Pike GB, Pitiot A, Richer L, Veillette S, Pausova Z, Paus T (2009) Sex differences in the growth of white matter during adolescence. Neuroimage 45:1055-1066. CrossRef Medline

Rametti G, Carrillo B, Gómez-Gil E, Junque C, Segovia S, Gomez Á, Guillamon A (2011a) White matter microstructure in female to male transsexuals before cross-sex hormonal treatment. A diffusion tensor imaging study. J Psychiatr Res 45:199-204. CrossRef Medline

Rametti G, Carrillo B, Gómez-Gil E, Junque C, Zubiarre-Elorza L, Segovia S, Gomez Á, Guillamon A (2011b) The microstructure of white matter in male to female transsexuals before cross-sex hormonal treatment. A DTI study. J Psychiatr Res 45:949-954. CrossRef Medline

Savic I, Garcia-Falgueras A, Swaab DF (2010) Sexual differentiation of the human brain in relation to gender identity and sexual orientation. In: Sex differences in the human brain, their underpinnings and implications (Savic I, ed), pp 41-61. Amsterdam: Elsevier.

Smith SM, Nichols TE (2009) Threshold-free cluster enhancement: addressing problems of smoothing, threshold dependence and localisation in cluster inference. Neuroimage 44:83-98. CrossRef Medline

Smith SM, Jenkinson M, Johansen-Berg H, Rueckert D, Nichols TE, Mackay CE, Watkins KE, Ciccarelli O, Cader MZ, Matthews PM, Behrens TE (2006) Tract-based spatial statistics: voxelwise analysis of multi-subject diffusion data. Neuroimage 31:1487-1505. CrossRef Medline

Swaab DF, Garcia-Falgueras A (2009) Sexual differentiation of the human brain in relation to gender identity and sexual orientation. Funct Neurol 24:17-28. Medline

Tournier JD, Mori S, Leemans A (2011) Diffusion tensor imaging and beyond. Magn Reson Med 65:1532-1556. CrossRef Medline

van Kesteren PJ, Gooren LJ, Megens JA (1996) An epidemiological and demographic study of transsexuals in The Netherlands. Arch Sex Behav 25:589-600. CrossRef Medline

Vos SB, Jones DK, Viergever MA, Leemans A (2011) Partial volume effect as a hidden covariate in DTI analyses. Neuroimage 55:1566-1576. CrossRef Medline

Wakana S, Caprihan A, Panzenboeck MM, Fallon JH, Perry M, Gollub RL, Hua K, Zhang J, Jiang H, Dubey P, Blitz A, van Zijl P, Mori S (2007) Reproducibility of quantitative tractography methods applied to cerebral white matter. Neuroimage 36:630-644. CrossRef Medline

Witte AV, Savli M, Holik A, Kasper S, Lanzenberger R (2010) Regional sex differences in grey matter volume are associated with sex hormones in the young adult human brain. Neuroimage 49:1205-1212. CrossRef Medline 